\title{
Catalytic metathesis of carbon dioxide with heterocumulenes mediated by titanium isopropoxide $\uparrow$
}

\author{
Rajshekhar Ghosh and Ashoka G. Samuelson* \\ Received (in Cambridge, UK) 25th November 2004, Accepted 26th January 2005 \\ First published as an Advance Article on the web 24th February 2005 \\ DOI: $10.1039 / \mathrm{b} 417713 d$
}

The insertion of an isopropoxide ligand of titanium isopropoxide into heterocumulenes gives a product that carries out metathesis at elevated temperatures by undergoing insertion of a second heterocumulene in a head to head fashion, followed by an extrusion reaction.

Formation of new carbon-carbon double bonds by a metal carbene catalyzed olefin metathesis has found wide utility in synthetic chemistry. ${ }^{1}$ Stoichiometric ${ }^{2}$ or catalytic ${ }^{3}$ exchange between multiply bonded substrates has recently been extended to carbonheteroatom double bonds. Vanadium oxo and imido complexes and group 14 complexes have been reported to be catalysts for the metathesis of phenyl isocyanate to give $N, N^{\prime}$-diphenylcarbodiimide and carbon dioxide. ${ }^{4}$ Carbodiimide metathesis is catalyzed by a number of complexes leading to the formation of unsymmetrical carbodiimides. ${ }^{5,6}$ Phosphoranes have also been shown to act as catalysts in the metathesis of carbodiimides. ${ }^{7}$ Metathesis of cumulenes with readily available greenhouse gases like carbon dioxide and carbon monoxide has gained importance as it can generate useful compounds like carbodiimides. ${ }^{8}$ Metathesis of carbon dioxide with carbodiimide leading to the formation of isocyanates has also been demonstrated. ${ }^{6,9}$ Recently Bergman et al. have shown the formation of a six membered metallacycle intermediate by insertion of an isocyanate into the $\mathrm{Ir}-\mathrm{N}$ bond of an iridium guanidinate in similar reactions. ${ }^{10}$

In this study we report the metathesis reactions of phenyl isocyanate, carbon dioxide, carbon disulfide and 1,3-diphenyl carbodiimide using titanium isopropoxide. Isopropoxide insertion is a key step in these reactions.

The insertion of heterocumulenes into titanium isopropoxides had been investigated by several workers in the 1970s. ${ }^{11,12}$ As part of our reinvestigation of the insertion of aryl isocyanates into titanium isopropoxides, the reaction was carried out at a higher temperature in refluxing toluene. Along with the inserted carbamates, we were surprised to find products formed from the insertion of isopropoxide into carbodiimide. Intermediate formation of carbodiimide would be possible if the metathesis of two isocyanate molecules took place. Formation of a six membered intermediate is likely if a second isocyanate is inserted into the initial insertion product (Scheme 1). Elimination of carbon dioxide through the formation of compound $\mathbf{1}$ would result in metathesis. This intermediate would be similar to that proposed by Bergman et al. in their reactions with isocyanates. The intermediate

$\dagger$ Electronic supplementary information (ESI) available: structure of 3a and $\mathbf{4 a}$, data on metathesis with aryl isocyanates and experimental details. See http://www.rsc.org/suppdata/cc/b4/b417713d/

*ashoka@ipc.iisc.ernet.in subsequently extrudes a different heterocumulene, other than the one which was inserted, leading to a metathesis reaction.

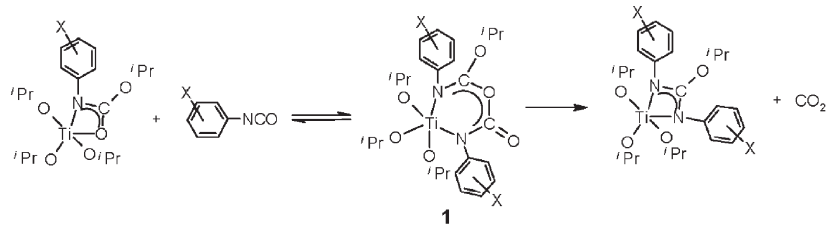

Scheme 1 Insertion of two molecules of ArNCO in a head to head fashion and elimination of carbon dioxide from $\mathbf{1}$.

The reaction of titanium isopropoxide and phenyl isocyanate led to the formation of a mixture of complexes (Scheme 2), which was not possible to separate. The complexes were hydrolyzed and the $\mathrm{TiO}_{2}$ removed by filtration. The organic products formed by insertion of the isopropoxide ligand into phenyl isocyanate (3a) were extracted and characterized. A small amount of (4a), formed by insertion of carbodiimide into a carbamate, was also isolated (for crystallographic characterization of $\mathbf{3 a}$ and $\mathbf{4 a}$ see ESI $\dagger$ ) $\dagger$.

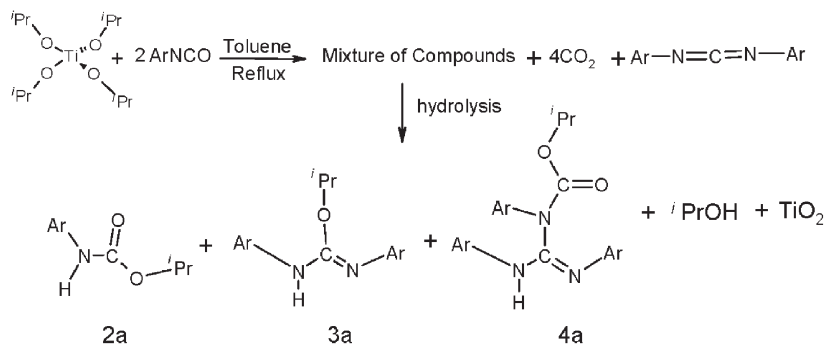

Scheme 2 Metathesis of two equivalents of aryl isocyanate with titanium isopropoxide and the products formed on hydrolysis of the reaction mixture.

To find out the effect of carbon dioxide elimination on the metathesis, the reaction was carried out in a sealed vial in an atmosphere of carbon dioxide using tetrahydrofuran as the solvent. As the system was rich in carbon dioxide, it suppresses the elimination of carbon dioxide and results in reduced metathesis and insertion products formed from insertion into the metathesis products. Thus only $27 \%$ of the metathesis product was observed in an atmosphere of carbon dioxide instead of $46 \%$ observed in its absence.

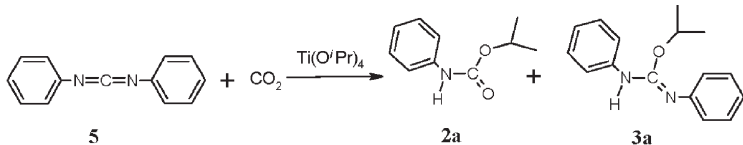


Table 1 Product ratio in metathesis between carbon dioxide with diphenyl carbodiimide

\begin{tabular}{|c|c|c|c|c|c|}
\hline Entry & $\begin{array}{l}\text { Amount of } \mathrm{CO}_{2}{ }^{a} \text { for } \\
\text { one equivalent of } \\
\text { diphenyl carbodiimide }\end{array}$ & Time/h & $2 a$ & $3 a$ & 5 \\
\hline 1 & $1.2 \mathrm{eq}$ & 24 & 36 & 52 & 5 \\
\hline 2 & 1.4 eq. $\mathrm{CO}_{2}$ & 24 & 45 & 50 & 5 \\
\hline 3 & 2.4 eq. $\mathrm{CO}_{2}$ & 12 & 72 & 23 & 5 \\
\hline 4 & 2.4 eq. $\mathrm{CO}_{2}$ & 48 & 75 & 22 & 5 \\
\hline
\end{tabular}

Since metathesis of phenyl isocyanate was suppressed in the presence of carbon dioxide, we decided to study the metathesis of carbon dioxide with other heterocumulenes such as diphenyl carbodiimide (eqn. (1)). These reactions were carried out in sealed vials in tetrahydrofuran as the solvent, at $110^{\circ} \mathrm{C}$. In the reaction of the carbodiimide and carbon dioxide, the metathesis product was phenyl isocyanate which was isolated as the inserted product (Table 1).

The product ratio was only dependent on the amount of carbon dioxide used in the reaction. Thus, doubling the amount of carbon dioxide resulted in twice the amount of $\mathbf{2 a}$ while the amount of $\mathbf{3 a}$ was reduced and the side product formed was not affected. The reaction had reached equilibrium in $24 \mathrm{~h}$ and continuing the reaction for a longer time $(48 \mathrm{~h})$ did not change the ratio of $2 \mathrm{a}$ and $\mathbf{3 a}$ (entries 3 and 4). The product ratios are thus equilibrium ratios and are not kinetically controlled.

In an attempt to probe the importance of insertion prior to metathesis, a metathesis reaction with carbon disulfide was attempted with carbodiimide. We have shown that carbon disulfide does not undergo insertion into titanium isopropoxide. ${ }^{13}$ Surprisingly small amounts of the metathesis product, phenyl isothiocyanate $(4 \%)$ and isopropyl phenyl thiocarbamate $(4 \%)$, were obtained upon insertion of isopropoxide into phenyl isothiocyanate, along with $87 \%$ of compound $\mathbf{3 a}$.

We have recently observed that the insertion product from carbon dioxide and titanium isopropoxide can be isolated only in the presence of trace quantities of water. ${ }^{14}$ In the absence of water, under the metathesis reaction conditions reported here with carbon dioxide and diphenyl carbodiimide, only insertion of diphenyl carbodiimide was possible. Metathesis between diphenyl carbodiimide and carbon disulfide or carbon dioxide probably occurs through the intermediate formed by insertion of diphenyl carbodiimide $^{12}$ followed by reaction with weakly coordinated carbon disulfide or carbon dioxide.

To find out if these metathesis reactions can be carried out in a catalytic fashion, the reactions were carried out with small
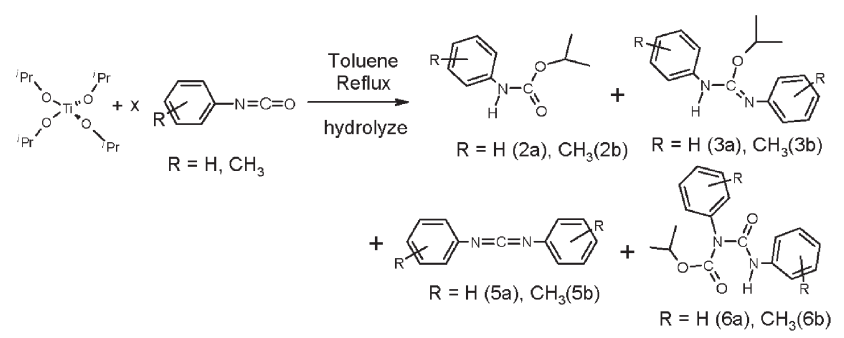

Scheme 3 Catalytic metathesis of aryl isocyanates to diaryl carbodiimides.
Table 2 Products obtained in catalytic metathesis and their isolated yields

\begin{tabular}{|c|c|c|c|c|c|c|c|}
\hline \multirow[b]{2}{*}{ Entry } & \multirow{2}{*}{$\begin{array}{l}\text { Amount and identity } \\
\text { of aryl isocyanate }{ }^{a}\end{array}$} & \multirow[b]{2}{*}{ Time/h } & \multicolumn{4}{|c|}{ Ratio of products } & \multirow{2}{*}{$\begin{array}{l}\text { - Isolated } \\
\text { yield }(\%)\end{array}$} \\
\hline & & & 2 & 5 & 3 & 6 & \\
\hline 1 & 20 eq. $\mathrm{PhNCO}$ & 24 & 29 & 57 & 4 & 10 & 84 \\
\hline 2 & 20 eq. 4 -TolNCO & 24 & 16 & 74 & 0 & 11 & 73 \\
\hline 3 & 40 eq. $\mathrm{PhNCO}$ & 48 & 18 & 70 & 0 & 12 & 76 \\
\hline 4 & 100 eq. $\mathrm{PhNCO}$ & 96 & 8 & 89 & 0 & 3 & 72 \\
\hline
\end{tabular}

quantities of titanium isopropoxide (Scheme 3). In the catalytic reactions, the isolated yield was moderate (Table 2). The unreacted isocyanate was generally isolated as the urea on workup. The yield was found to decrease when the reaction was carried out with higher amounts of isocyanates. Surprisingly, the isolated yield was lower for the 4-methylphenyl isocyanate in comparison with the phenyl isocyanate under similar conditions. These reactions show that titanium isopropoxide can be utilized to catalytically convert isocyanates to the carbodiimides.

In summary, we have encountered a metathesis reaction that could be of considerable value in utilizing carbon dioxide. Metathesis and insertion products can be isolated when stoichiometric amounts of aryl isocyanates and titanium isopropoxides react with each other in refluxing toluene. Elimination of carbon dioxide is a key step. Since the reaction is completely reversible, the metathesis of carbodiimides with carbon dioxide can be conducted leading to the formation of isocyanates. The metathesis reaction is faster for heterocumulenes which insert readily. It also occurs between two heterocumulenes when one of them inserts, whereas the other only reacts with the first insertion product and not with the isopropoxide. We have demonstrated that this reaction can be carried out in a catalytic fashion.

We acknowledge the Department of Science and Technology, India (DST) for financial support and FIST program of the DST for the $400 \mathrm{MHz}$ NMR facility.

Rajshekhar Ghosh and Ashoka G. Samuelson* Department of Inorganic and Physical Chemistry, Indian Institute of Science, Bangalore 560 012, India. E-mail: ashoka@ipc.iisc.ernet.in; Fax: 91-80-23601552; Tel: 91-80-22932663

\section{Notes and references}

t Compound 3a: $\mathrm{C}_{16} \mathrm{H}_{18} \mathrm{~N}_{2} \mathrm{O}, M=254.3$, triclinic, $a=8.9335(18) \AA$, $b=9.5181(19) \AA, c=9.5609(19) \AA, \alpha=110.127(3)^{\circ}, \beta=99.664(3)^{\circ}$, $\gamma=101.080(3)^{\circ}, V=724.5(3) \AA^{3}, 293(2) \mathrm{K}$, space group $P \overline{1}, Z=2$, $\mu=0.074 \mathrm{~mm}^{-1}, 7559$ reflections measured, 2835 independent reflections $\left(R_{\text {int }}=0.0594\right)$ which were used for all calculations, $R 1=0.0496$, $w R 2=0.1292$ (observed data). Compound 4a: $\mathrm{C}_{23} \mathrm{H}_{23} \mathrm{~N}_{3} \mathrm{O}_{2}, M=373.44$, triclinic, $a=9.505(5) \AA, b=10.689(6) \AA ⿻$, $c=10.748(6) \AA, \alpha=81.385(9)^{\circ}$, $\beta=71.862(9)^{\circ}, \gamma=88.352(9)^{\circ}, V=1025.9(10) \AA^{3}, 293(2) \mathrm{K}$, space group $P \overline{1}, Z=2, \mu=0.078 \mathrm{~mm}^{-1}, 10794$ reflections measured, 4038 independent reflections $\left(R_{\text {int }}=0.0563\right)$ which were used for all calculations, $R 1=0.0398$, $w R 2=0.0982$ (observed data). CCDC 252216 and 252217. See http:// www.rsc.org/suppdata/cc/b4/b417713d/ for crystallographic data in .cif or other electronic format.

1 R. H. Grubbs and S. Chang, Tetrahedron, 1998, 54, 4413; M. Schuster and S. Blechert, Angew. Chem., Int. Ed. Engl., 1997, 36, 2036; R. H. Grubbs and W. Tumas, Science, 1989, 243, 907.

2 K. E. Meyer, P. J. Walsh and R. G. Bergman, J. Am. Chem. Soc., 1994, 116, 2669; K. E. Meyer, P. J. Walsh and R. G. Bergman, J. Am. Chem. 
Soc., 1995, 117, 974; W. Wang and J. H. Espenson, Organometallics, 1999, 18, 5170; M. L. H. Green, G. Hogarth, P. C. Konidaris and P. Mountford, J. Organomet. Chem., 1990, 394, C9; D. L. DeLaet, P. E. Fanwick and C. P. Kubiak, J. Chem. Soc., Chem. Commun., 1987, 1412; R. L. Zuckerman and R. G. Bergman, Organometallics, 2000, 19, 4795.

3 G. K. Cantrell and T. Y. Meyer, Organometallics, 1997, 16, 5381; G. K. Cantrell and T. Y. Meyer, J. Am. Chem. Soc., 1998, 120, 8035; R. L. Zuckerman, S. W. Krska and R. G. Bergman, J. Am. Chem. Soc., 2000, 122, 751; S. W. Krska, R. L. Zuckerman and R. G. Bergman, J. Am. Chem. Soc., 1998, 120, 11828; K. R. Birdwhistell, J. Lanza and J. Pasos, J. Organomet. Chem., 1999, 584, 200; S. Y. Lee and R. G. Bergman, J. Am. Chem. Soc., 1996, 118, 6396.

4 K. R. Birdwhistell, T. Boucher, M. Ensminger, S. Harris, M. Johnson and S. Toporek, Organometallics, 1993, 12, 1023; J. R. Babcock and L. R. Sita, J. Am. Chem. Soc., 1998, 120, 5585; J. R. Babcock, C. Incarvito, A. L. Rheingold, J. C. Fettinger and L. R. Sita, Organometallics, 1999, 18, 5729; J. R. Babcock, L. Liable-Sands, A. L. Rheingold and L. R. Sita, Organometallics, 1999, 18, 4437.

5 I. Meisel, G. Hertel and K. Weiss, J. Mol. Catal., 1986, 36, 159; K. Weiss and K. Hoffmann, Z. Naturforsch., 1987, 42b, 769; K. Weiss and P. Kindl, Angew. Chem., 1984, 96, 616; K. Weiss, Stud. Surf. Sci. Catal., 1984, 19, 397.

6 L. R. Sita, J. R. Babcock and R. Xi, J. Am. Chem. Soc., 1996, 118, 10912; R. Xi and L. R. Sita, Inorg. Chim. Acta, 1998, 270, 118.
7 S. A. Bell, S. J. Geib and T. Y. Meyer, Chem. Commun., 2000, 1375; S. A. Bell, T. Y. Meyer and S. J. Geib, J. Am. Chem. Soc., 2002, 124, 10698; M. C. Burland and T. Y. Meyer, Inorg. Chem., 2003, 42, 3438.

8 L. Guczi, Studies in Surface Science and Catalysis: New Trends in CO Activation, Elsevier, New York, 1991, vol. 64; D. H. Barton, A. F. Martell and D. T. Sawyer, The Activation of Dioxygen and Homogeneous Catalytic Oxidation, Plenum Press, New York, 1993; A. Williams and I. T. Ibrahim, Chem. Rev., 1981, 81, 589; R. Muthyala, in Comprehensive Organic Functional Group Transformations, ed. A. Katritzky, O. Meth-Cohn and C. W. Rees, Pergamon, New York, 1995, vol. 5, pp. 1061-1089 and pp. 1161-1308.

9 W. Y. Kim, J. S. Chang, S. E. Park, G. Ferrence and C. P. Kubiak, Chem. Lett., 1998, 1063; W. Y. Kim, J. S. Chang, S. E. Park and C. P. Kubiak, Res. Chem. Intermed., 1999, 25, 459.

10 A. W. Holland and R. G. Bergman, J. Am. Chem. Soc., 2002, 124, 9010.

11 P. C. Bharara, V. D. Gupta and R. C. Mehrotra, J. Indian Chem. Soc., 1974, 51, 859; B. L. Gorsi, P. N. Kapoor and R. C. Mehrotra, Indian J. Chem., 1975, 13, 1200.

12 O. Meth-Cohn, D. Thorpe and H. J. Twitchett, J. Chem. Soc. C, 1970, 132.

13 R. Ghosh, M. Nethaji and A. G. Samuelson, J. Organomet. Chem., 2005, 690, 1282-1293.

14 R. Ghosh, M. Nethaji and A. G. Samuelson, Chem. Commun., 2003, 2556. 